\title{
Big History in its Cosmic Context
}

Joseph Voros

Swinburne Business School

Faculty of Business and Law

Swinburne University of Technology

\section{Abstract}

Current models of Big History customarily take the observed increases over cosmic time of material-energetic complexity as their central concept. In this paper, we use Erich Jantsch's pioneering masterwork The SelfOrganizing Universe as the primary perspective from which to extend the customary 'increasing materialenergetic complexity' view of Big History in two principal 'directions'. Firstly, outwards, with an emphasis on increasing scale, scope and context to consider whether non-terrestrial analogues of Big History might exist or have existed elsewhere, and thus to embrace the 'sibling' multidisciplinary fields of SETI (the search for extraterrestrial intelligence), Astrobiology, and 'Cosmic Evolution'. And secondly, inwards, with a focus on (human) consciousness and the increasing complexity of human cognitive experience ('interiority') that has been apparent over the time-frame we have been able to observe it. Since Big History is a narrative which necessarily includes our own awakening to conscious awareness - and the felt sense of 'meaning' which our interiority brings with it - it would be valuable to examine related models which might also allow for an integration or unification of the two perspectives of physical-objective material-energetic complexity, on the one hand, and the complexity of subjective-conscious interiority, on the other. This is important, because it might provide a pathway that could help resolve recent debates around whether, and if so where, 'meaning' might reside in Big History. Current models do not tend to have a clear way to do this, so a particular integrative framework is introduced and outlined - due to the philosopher of consciousness Ken Wilber-which seeks to unify the customary complexity of matter-energy view of Big History with a 'complexity of consciousness' view, and which thereby suggests a very natural way to resolve the question of meaning 'in' Big History. It also provides a useful framework for thinking about a third direction of exploration, namely onwards, towards the future of our civilisation (and even our species), in both explicit and implicit modes, each of which are also briefly outlined. We end with a dedication to the memory of Erich Jantsch and his work.

\section{Keywords}

Big History, SETI (Search for Extra-Terrestrial Intelligence), Astrobiology, Cosmic Evolution, Consciousness, Interiority, Integral Model of Consciousness, 'Meaning' in Big History, Erich Jantsch, Ken Wilber.

Correspondence | Joseph Voros, jvoros@swin.edu.au

Citation | Voros, J. (2019) Big History in its Cosmic Context. Journal of Big History, III(3); 57 - 80.

DOI | https://doi.org/10.22339/jbh.v3i3.3340

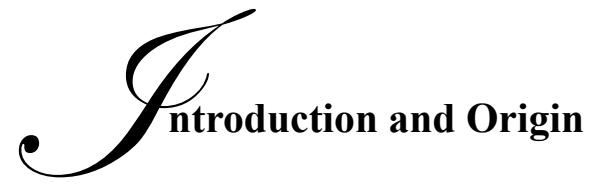

Big History represents an increasingly-visible and -popular approach to the modern scientifically-based understanding of how humankind came to be herewhat David Christian (2018) has notably called an "origin story". It is both a very powerful conceptual model - usually based upon the foundational concept of increasing material-energetic complexity over cosmic time-scales - as well as a very engaging narrative that helps us to make sense of the entirety of the past, literally, from the beginning of the Universe with the Big Bang nearly 14 billion years ago to our present-day planet-wide informationbased technological civilisation (e.g., Brown 2008, 2017; Chaisson 2001, 2007, 2008; Christian 2004, 2008, 2018; Christian, Brown \& Benjamin 2013; Delsemme 1998; Jantsch 1980; Spier 1996, 2010, 2015). In my own Big History teaching, I sometimes like to describe this as a narrative that leads "from 
hydrogen to humanity" (prompted by a comment by Carl Sagan; see later) or, alternatively, "from quarks to consciousness" (about which latter I will have much to say below). In the more measured and less colloquial language of the International Big History Association (2016), Big History "seeks to understand the integrated history of the Cosmos, Earth, Life, and Humanity, using the best available empirical evidence and scholarly methods".

There have been many earlier attempts to bring together synoptic views of the history of the Universe or of the totality of what is known about it. Big History pioneer Fred Spier has discussed some of these in the first chapter of both (so far) editions of his recent major theoretical work on the structure of Big History (Spier 2010, 2015), to which the reader is referred for a more detailed exploration. As Spier (2015, p. 26) notes, however, it was Erich Jantsch (1980) who developed perhaps the first systematic model of Big History based upon the modern understanding of the principles of the non-equilibrium thermodynamics of dissipative structures in what has come to be known - and not without some disagreement over the use of the term, e.g., Chaisson (2014, sect. 5.1) - as 'self-organisation'. It remains a stunning example of multidisciplinary integrative scholarship even after four decades, and anyone who is interested in a deeper understanding of the multi-level and multi-scale physical processes underlying Big History would do well to get hold of a copy. ${ }^{1}$

Accordingly, in this paper, Jantsch's seminal pioneering work will serve as the foundational framing perspective for some ideas and discussion around how to extend the customary 'increasing materialenergetic complexity' view of Big History in what I hope are fruitful lines of thinking. I propose to do this in two main ways, or in two principal 'directions': outward, with an emphasis on increasing scale, scope

1 Even second-hand copies tend to be quite expensive (some ridiculously so!), but, luckily, it appears to be possible (at least at the time of this writing) to download a free PDF copy from https://monoskop.org/File:166495032-The-Self-OrganizingUniverse-by-Erich-Jantsch.pdf and context to consider whether other non-terrestrial analogues of Big History might exist or have existed; and inward, with a focus on (human) consciousness and the increasing complexity of human cognitive experience ('interiority'). Since Big History is, in a very literal sense, 'our' story - a story which of necessity includes as part of it our own awakening to consciousness and the sense of 'meaning' this awareness has brought with it - it would be valuable to examine any suitable related models which might also allow for any putative integration or unification of the perspectives of increasing physical-objective materialenergetic complexity, on the one hand, with increasing complexity of subjective-conscious interiority, on the other. And there are very good reasons for attempting to do so.

Those who were present at the 2014 IBHA Conference at Dominican University in San Rafael would know of the tensions that ensued there around the issue of 'meaning' in Big History, tensions that existed to a greater or lesser degree in various sessions right up to the very last session itself, the final plenary panel discussion (Gustafson et al. 2014). A question was asked by Laura Rahm during that final plenary regarding the variety of approaches to and interpretations of Big History that were evident in the conference program, some of which were openly considered problematic. Along with a couple of the other panellists, I offered some ideas in answer to Laura's question, and mentioned (I think) that "one of these years" when I got time I would probably write something up. Well, I think that perhaps it is now high time to elaborate on the conceptual model informing what I said in that session. ${ }^{2}$

These debates about 'meaning' in Big History can hopefully be accommodated within a view and model to be presented in outline below-primarily through the simple observation that 'meaning' can be regarded

2 This paper is the first of a planned pair of papers that are intended to lay out my personal conception of Big History and how I understand both its broad contours, as well as its place in the cosmic scheme of things. This paper deals with the latter of these. The follow-up paper will deal with the former. 
as existing (as it were) 'in here' (i.e., inside our own consciousness or interiority) without requiring it to necessarily exist independently 'out there' in the wider Universe, which proposition was then and is still quite unpalatable to many scientists, especially physical scientists (such as I was trained to be). Hence, part of the purpose of this paper is to begin to attempt to bring together (to the degree possible) some of the disparate perspectives held on this issue under the umbrella of a unifying framework which potentially allows these different viewpoints to co-exist in a mutuallysupportive way, even as they might disagree on certain specifics and relative emphases. Of course, it remains to be seen how successful that will be; but it is, I think, still well worth the effort to try. I take heart from the observation that Big Historians as a group tend to be well accustomed to and supportive of allowing for different relative emphases of different parts of the Big History narrative among their colleagues, given that we all tend to share a common interest in and commitment to disseminating the overall general account of Big History, even as we might tend personally to focus in deeper detail on only part(s) of it.

Now, as noted above, current models of Big History usually take as their foundational concept the observed increases over cosmic time-scales of materialenergetic complexity. But these models do not tend to have a clear way to also include due consideration of the observed increases in the complexity of human cognitive experience over the time-frame that we have been able to observe it. To this end, therefore, a particular model of Big History will be presented which seeks to unify the usual material-energeticcomplexity view of Big History-founded on the physical sciences, especially physics and chemistry, and understood in a most profound and insightful way through the seminal work of Erich Jantschwith an 'increasing complexity of interiority' view, which has recently emerged from the humanitiesespecially psychology and anthropology, drawn from the synthesising theoretical work of the philosopher of consciousness Ken Wilber. Such a unifying or integrating framework has at least the potential to do justice to the enduring insights and truths from the physical and social sciences while also incorporating the emerging insights and theoretical advances which have come to light over the last century or so of research into human psychology and culture; this is principally why it is being presented and outlined here.

In the next section, then, a few key aspects of Jantsch's work will be presented as the basis and primary framing perspective for our further discussions. This perspective is then expanded in the 'outward' direction towards 'outer space' to include the over-arching 'sibling' fields of SETI (the search for extra-terrestrial intelligence), astrobiology, and 'cosmic evolution' as a whole (the 'nesting' of which perspectives will be elucidated in more detail below). Following that, the direction of our exploration then reverses 'inwards', towards the 'inner space' of our interior consciousness and culture, and Wilber's 'integral' framework is thereby presented as one possible natural extension to Jantsch's perspective which fully embraces, incorporates and broadens it. This high-level model of "orienting generalisations" (as Wilber often has it) also turns out to provide a very useful framework for thinking about a third direction of exploration, namely, the 'onward' direction of the future of our civilisation (and even our species) - from a 'macro' perspective commensurate with the scope and perspective of Big History-via two main modes, 'explicit' and 'implicit', which are each also outlined. Some concluding remarks revisit the principal ideas in summary, and we end with a dedication to the memory of Erich Jantsch and his work, as well as a call-to-action to further continue the multidisciplinary synthesising work which he embarked upon.

Now, though, let us begin our re-framing of the customary Big History viewpoint, in order to see what new insights and perspectives we might yet uncover or bring into view as we slightly shift our usual frame of reference... 


\section{The Frame, part 1 \\ Erich Jantsch - The Self-Organizing Universe and The Evolutionary Vision}

Erich Jantsch spent the last part of his much-tooshort life thinking deeply about the future directions of human civilisation and how it might be more purposefully guided with wisdom and perhaps even with foresight. Over an immensely prolific period of a mere decade and a half or so, his considerable intellect and attention ranged from, initially, technological forecasting (Jantsch 1967), technological planning and social change (Jantsch 1969b, 1972b), and the design of and planning in human systems (Jantsch 1969a, 1972a, 1975), to, ultimately, a deeper view of human evolution, consciousness, self-organisation and even self-transcendence (Jantsch \& Waddington 1976), culminating in a unifying vision of evolutionary selforganisation at multiple scales of complexity, brought together in his masterwork The Self-Organizing Universe (Jantsch 1980), with a subsequent edited volume, The Evolutionary Vision (Jantsch 1981b), published soon after his untimely death.

The Self-Organizing Universe (hereafter SOU) attempted to describe-using nonequilibrium thermodynamics as its foundational framework - the fundamental physical processes that give rise to new emergent properties at each new distinctlypersisting level of complexity, a quasi-stable dynamical "process structure" he also called a régime (p. 21ff). Spier (1996, p. 14), too-independently and unaware of Jantsch's use of the termalso used the term regime for his approach to Big History (Spier 2015, p. 68n4). The relationship of Jantsch's and Spier's 'regimes' to Christian's (2004) well- known concept of 'thresholds' can most easily be understood as essentially analogous to that of the distinction between the floors of a building and the stairs connecting them: the floors are the quasi-stable regimes, while the transitions between floors are the thresholds of step-changes in complexity which give rise to new emergent properties on each floor. Both are useful ways of viewing the overall structure of the building, but one or other view may be relatively more useful depending upon the particular focus taken and/or the specific aspect of Big History under investigation. They are, in other words, complementary and coexist as essentially a 'figure-ground' pair. (See, e.g., Fig. 1 in Aunger 2007, pp. 1141, for a rough schematic sketch of this general idea.)

One of the very many key ideas in $S O U$ is the simultaneous co-evolution of both 'microstructures' and 'macrostructures' - that is, of individual entities making up macroscopic collections or collectives of such entities - brought about by the dynamical processes set in motion after the Big Bang, in part by the asymmetry of the arrow of time caused by the

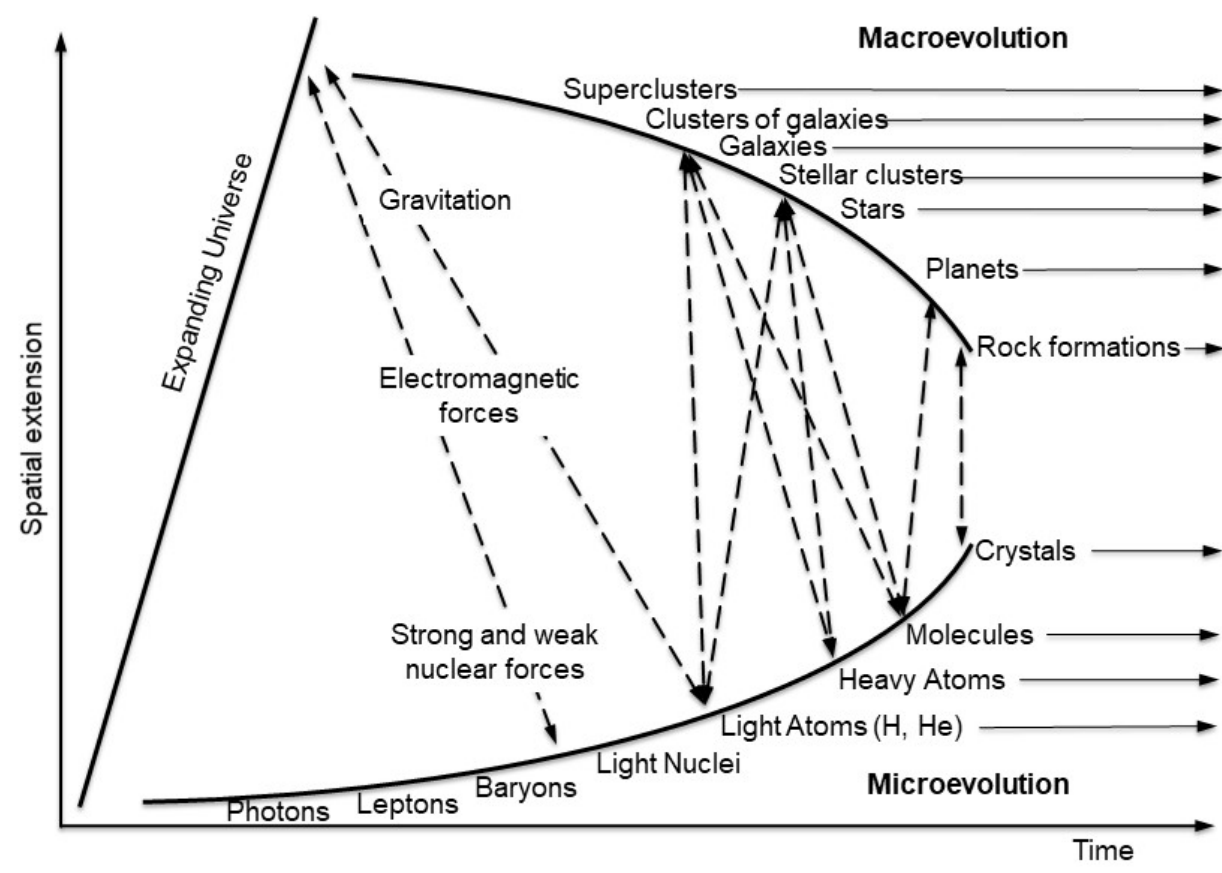

Figure 1. "Cosmic evolution of macro- and micro-structures. ... These levels mutually stimulate their evolutions."

Source: Recreated by the author from Jantsch (1980, Fig 24, p. 94.) 
expansion of the Universe. Thus, in Figure 1 (taken from Jantsch 1980, Fig. 24, p. 94), we see how the smaller microstructures of 'microevolution' on the bottom of the figure become more complex-sub-atomic particles form into light nuclei which form into light atoms which form into heavier atoms which form into molecules, and so on-while the corresponding macrostructures also evolve in a co-evolutionary process of 'macroevolution' along the top of the figuremost recognisably, as galaxies to stars to planets, and so on.

The converging arcs in Figure 1 are intended to show that spatial scale is decreasing over time for the macrostructuresgalaxies are smaller than clusters of galaxies, stellar clusters smaller than galaxies, stars are smaller than stellar clusters, planets are smaller than stars, and so on-while the spatial scale is increasing over time for the microstructures - atoms are larger than nuclei, molecules are larger than atoms, and so on. These are all physical structures undergoing physical changes, and Jantsch calls this overarching dual-scale process of physical change 'cosmic evolution', a term that has since that time come to be used by an increasing number of researchers to mean a somewhat broader process than the merely physical, something discussed further below.

This process of dynamical-evolutionary change continued on planet Earth beyond merely physical structures, as is shown in Figure 2, wherein the increasing complexity of distinctly biological entities is now also evident-prokaryotes to eukaryotes to multicellular organisms to complex animals, in the micro-evolutionary branch-along with the corresponding macrostructures - the Gaia system to heterotrophic ecosystems to societies with divisions of labour (i.e., specialisations of functions in multicellular organisms) to groups and families of complex animals, in the macro-evolutionary branch. Here, too, spatial extent similarly shows the decreasing/increasing trajectories of macro and micro, respectively.

In this phase of what Jantsch calls "sociobiological evolution" the dominant direction of interaction between macro and micro co-evolution is principally from the macro to the micro. That is, the macrostructural branch influences the entities on the micro-evolutionary branch to a much, much larger degree than the reverse case. This is depicted in the left half of Figure 3 by the bold arrows extending downwards from the macro and the much thinner arrows extending upwards from the micro. Intuitively, this makes sense, since an organism must adapt to the environmental milieu in which it finds itself or else it risks extinction. But this dominance by the macro over the micro in this phase of the universal co-evolutionary process is about to change, as is shown in the centre of Figure 3, which also depicts the third main phase 


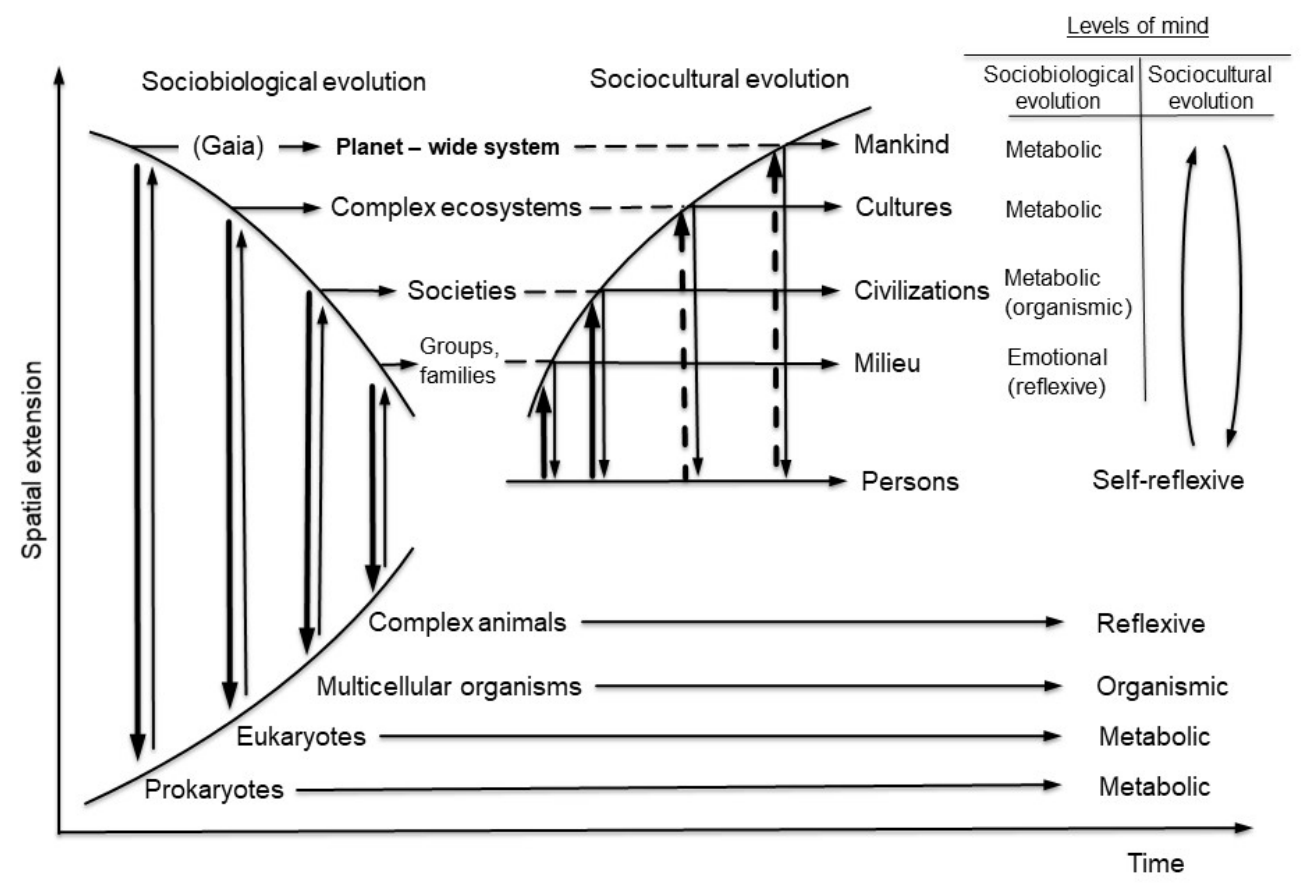

Figure 3. "The transition from the sociobiological to the sociocultural phase of evolution turns things upside down, as far as the dominant relationships in the coevolution of macro- and micro-systems are concerned. Self-reflexive mind ... sets out to re-create the macroworld. ... [A]t the levels of culture and mankind-at-large, this is still a partially conscious process only."

Source: Recreated by the author from Jantsch (1980, Fig 32, p. 175.) of universal co-evolution - the "sociocultural" phase.

In sociocultural evolution, the dynamic 'flips'micro starts to push back on and influence the macro much more strongly than prior. Rather than only adapting ourselves to suit the environmental milieu (which we were very good at, truth be told, which is why we were able to walk to the ends of the Earth, literally, in only a few tens of thousands of years), we also set out to adapt the environment to suit ourselves, an ability that has become increasingly powerful and pervasive during our tenure here on planet Earth. Beginning slowly in the Palaeolithic, we began to modify to an increasing extent the environments we found ourselves in, and then most definitely once the process of 'extensification' (cf., e.g., Christian 2004, p. 190ff) began to run down and forced us to become increasingly sedentary. The process of increasing intensification of food production in situ is of course none other than the transition to agriculture itself
(Christian's 'Threshold 7'), and the present global-scale crises we are experiencing can be considered as merely the natural endpoint of that process of, as Jantsch puts it in the caption to Fig. 3, "self-reflexive mind setting out to re-create the macroworld". Once Mankind expanded to become a planetwide system comparable to Gaia itself (cf. Fig. 3), then something like an 'Anthropocene' epoch (Zalasiewicz, Crutzen \& Steffen 2012) is therefore seen to be an almost inevitable result of this sort of dynamic, especially since our influence on the planet is still only (as Jantsch notes) "a partially conscious process" (albeit now slowly becoming more so).

One can see in these three remarkable diagrams essentially the entire process of Big History laid out graphically-from the Big Bang and the expansion of the Universe, to the formation of atoms, galaxies, stars and planets, to the emergence and evolution of life (on Earth), to the subsequent arising of humans, as well as the increasing agency of humanity bumping up against the limits of the biosphere - all driven by an underlying process of increasing complexity of material-energetic structural organisation and informational flows, resulting from energy gradients driving non-equilibrium thermodynamic systems processes of dissipative selforganisation (gasp!).

It is in this way that Jantsch's (r)evolutionary vision was able to bring together so much of the history of the cosmos into a coherent process view based on a few key ideas and principles. Thus, we can see clearly how non-equilibrium thermodynamical processes of ever- 
increasing complexity are seen to underlie the entirety of Big History - the means by which the evolutionary processes of the Universe gave rise to us - which Jantsch portrayed through the three main phases of evolution he depicted: cosmic (i.e., astrophysical), sociobiological and sociocultural.

Jantsch died in December 1980 just under a month hort of his $52^{\text {nd }}$ birthday (Capra 1981; Linstone, Maruyama \& Kaje 1981; Zeleny 1981) and did not live to see his final work published - the edited volume The Evolutionary Vision (Jantsch 1981b) in which he laid out his (as it turns out) final views on the "new emerging paradigm" of evolutionary selforganisation:

... the greatest importance of today's evolutionary vision may lie not in its present propositions and concepts, but in the new questions it poses in many areas of scientific endeavour and especially in the unifying transdisciplinary 'pull' it exerts in these areas. (p210)

Of [great] importance will be a precise formulation of the relations between biologicall ecological/sociobiological evolution on the one hand and psychological/sociocultural evolution on the other. ... The evolutionary vision opens up the possibility of understanding all creative dynamics in a unified way. (p212) (emphasis added here).

Or, as Zeleny noted (1981, p. 120), quoting Jantsch's "last article" (Jantsch 1981a):

The new paradigm of self-organization, and with it the focal concept of autopoiesis, ends the alienation of science from life. It forms the backbone of an emergent science of life that includes a science of our own lives, the biological as well as the mental and the spiritual aspects, the physical as well as the social and the cultural.

We shall turn to a version of that unifying view in due course below. In the meantime, let us now look at how we might expand our view beyond our own specific case to consider whether other possible instances of the same universal co-evolutionary processes that gave rise to us might also have occurred elsewhere....

\section{Outward}

\section{'Cosmic Evolution'}

In the decades since Jantsch wrote, the term cosmic evolution has come to be used (often by astronomers, astrobiologists and some other multidisciplinary scientists) to mean not merely the physical segment of this overall multi-phase process, but rather the entirety of the evolution of the cosmos itself through all of these (at least) three distinct phases (see, e.g., Dick 2009). So it was, for example, that Carl Sagan (1980, p. 338) would say, referring to the process leading from the Big Bang to us in chapter/episode 13 of his book/TV series Cosmos, that: "these are some of the things that hydrogen atoms do given fifteen billion years of cosmic evolution" (and hence my epithet "from hydrogen to humanity", above). Eric Chaisson $(1979,2001)$ has also used the term for decades in the same broad manner when referring to the overarching general processes of increasing complexification leading "from the big bang to humankind" (e.g., Chaisson 2008). Some authors, however (e.g., Grinin et al. 2011), and notably Spier (e.g., 2015, ch. 3), continue to use the term 'cosmic evolution' in the same way Jantsch used it - referring to the physical processes alone. This is of course a perfectly legitimate use of the terminology, provided one is very clear about what is being referred to by it, notwithstanding that its initial use by Jantsch has since largely been overtaken by the broader meaning used by an increasing number of researchers and scholars in recent years. For my own part, I too prefer to use the term 'cosmic evolution' in the broader sense of Chaisson, Sagan, and Dick, and prefer to instead use the terms physical, astrophysical, material or even cosmological evolution for the more specific and restricted sense of the term as used by Jantsch, Spier, Grinin and others.

Now, there is more to this than mere terminological hair-splitting, however, for when one thinks about this carefully, it should be clear that 'Big History' is ultimately concerned with the history of just one planet—ours - among the trillion or so that are now 
thought to exist in the Milky Way Galaxy, not to mention the hundreds of billions of trillions that can thereby be inferred to exist in the wider observable universe. As Chaisson (1979, p. 38) put it, "if the processes of cosmic evolution outlined here are valid, then they apply to every nook and cranny of the universe", and therefore, "should the scenario of cosmic evolution be valid, even in its broadest perspective, we can speculate rightfully about the associated implication for the plurality of extraterrestrial life" (p. 24).

Thus, from this perspective, this "scenario of cosmic evolution" (Chaisson) can, and perhaps even should, be considered a universal nomothetic process-a process which could apply (at least in principle) throughout the Universe, rather than being regarded simply and merely the (singular) idiographic case of how we arose through the evolutionary dynamics of the developing Cosmos on this planet in this galaxy. In other words, in this view, 'Cosmic Evolution', as such, is to be regarded as a general universal process, while 'Big History' is to be regarded as really just our particular instance or unfolding of that general universal process. We are, then, a single instance in the even larger context of what may be countless other instances of the unfolding of the general theme(s) of Cosmic Evolution potentially occurring throughout the Cosmos - what Sagan (1980, ch. 2) so poetically called "one voice in the cosmic fugue". In this view, therefore, whereas 'Big History' is concerned with specifically 'Cosmos, Earth, Life, and Humanity' (per the IBHA), 'Cosmic Evolution' is concerned more generally with 'Cosmos, Planet, Life, and Intelligence', wherever and however that process may play out. For my part, I find it very easy indeed to imagine the possibility of the existence of other planets where life, and perhaps even intelligence, has arisen, as the Cosmic-Evolutionary scenario might have unfolded there to varying degrees, potentially giving rise to those beings' own unique variants or analogues of (what we call our) Big History.

\section{Astrobiology, SETI}

This extended perspective now brings clearly into view the closely-related multi-disciplinary 'sibling' fields of SETI, the Search for Extra-Terrestrial Intelligence (e.g., Ekers et al. 2002; Harrison 2009; Morrison, Billingham \& Wolfe 1979; Shklovskii \& Sagan 1966; Tarter 2001, 2004; Tarter et al. 2010), and Astrobiology, the study of how life might arise and evolve in the Universe (e.g., Chyba \& Hand 2005; Domagal-Goldman et al. 2016; Mix et al. 2006). In this expanded conception, then, we are-here on our "pale blue dot" (Sagan 1995) — simply a single 'element' (in the language of set theory) of what may be a set of intelligent technology-using civilisations, which itself forms a sub-set of intelligent lifeforms in general (i.e., not necessarily technology-using), which itself forms a sub-set of lifeforms in general (i.e., not necessarily intelligent), which arise on places/planets where lifeforms could arise (i.e., habitable planets, in general). This, in turn, forms a sub-set of all places/ planets in the Milky Way Galaxy, which is but one galaxy among perhaps a hundred billion or so in the observable Universe, which is but a small part of what may be an immensely-large, and perhaps even infinite, Universe. And, according to more recent thinking, our Universe may itself simply be one among an uncountable number of other universes in an even larger 'multiverse' of indeterminate and probably unimaginable extent (e.g., Hawking \& Mlodinaw 2010). The image of nested Russian 'Matryoshka dolls' is almost irresistibly called to mind.

One can imagine this nested progression (at least in our Universe) in at least two ways: one as a series of potential trajectories passing through the various phases of Cosmic Evolution-_cosmological/material/ astro)physical, biological, and (socio)cultural (which also clearly includes technological as a possible sub-phase); and the other as a nested series of sets each containing a potential number of elements/ instances, as above. Unfortunately, however-at least, so far, at the time of this writing - the known instances of both of these conceptions number only 
one, but I do nonetheless (very scientifically!) have my fingers crossed! The 'progression through phases' conception is most clearly embodied in the wellknown Drake Equation of SETI, which is intended to yield an estimate of the number $N$ of existing technological civilisations in the Milky Way Galaxy both capable of and willing to undertake interstellar radio communication (Drake 1961). Steven Dick (2003) notes that the Drake Equation can be written as the product of three main types of terms, as shown in Equation (1), as was also very clearly implied by Jantsch's work in SOU. The number $N$ of extant communicating technological civilisations is given by:

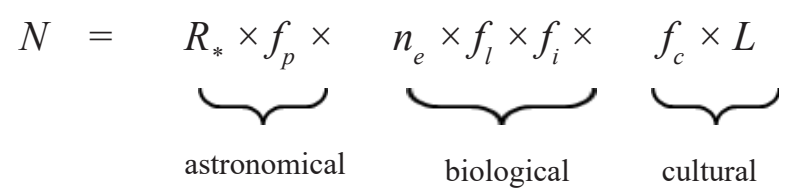

where $R_{*}$ is the average rate of star formation in the Galaxy; $f_{\mathrm{p}}$ is the fraction of those that have planets; $n_{\mathrm{e}}$ is the average number of planets in each of these star systems with conditions favourable to life; $f_{l}$ is the fraction of these planets that go on to actually develop life; $f_{\mathrm{i}}$ is the fraction of these inhabited planets that go on to develop intelligent life; $f_{\mathrm{c}}$ is the fraction of planets with intelligent life that develop technological civilizations capable of interstellar communication; and $L$ is the average communicative lifetime of such a civilization.

There have been many extensions to the Drake Equation and its terms since it was first written down (see, e.g., the related discussion in Voros 2017), including, more recently, by Claudio Maccone (2010) who notably expanded the customary conception of the Drake Equation as the product of seven static positive numbers representing the various terms, to their being considered as variables which may take arbitrary random (albeit positive) values-a considerable extension of the original conception.

In other words, the broad process of Cosmic Evolution encompasses several distinct phases of evolution: Physical, Biological, Cultural, and indeed,
Technological, which one might denote by $\mathbf{P}, \mathbf{B}$, $\mathbf{C}$ and $\mathbf{T}$, respectively. As noted, the only known instance, so far, of the Cosmic Evolution process/ scenario moving through all of these phases P-BC-T, is us: Big History, 'BH'. If we denote by $\mathcal{K}$ the set of all known (to us) instances of the full Cosmic Evolutionary scenario moving through all the phases P-B-C-T, and also imagine another set, denoted by $A$, of all actual-both those known-to-us and those as-yet-unknown-to-us - instances of the full Cosmic Evolutionary scenario, then, clearly, $\mathcal{K}$ is either a proper sub-set of, or is equal to, $A$, thus: $K \subseteq A$. Hence, at this point in time, $\mathcal{K}$ is a set containing only a single element, $K=\{\mathrm{BH}\}$. From a set-theoretical point of view, therefore, it could also be the case that $\mathrm{BH}$ is the only member of $\boldsymbol{A}$ as well, but this cannot be rigorously concluded - there is always the possibility of the existence of other elements of $A$ which are not yet part of $\mathcal{K}$. This distinction, while it may appear to be simply mathematical-logical sophistry, is nonetheless a very important point, because it forces us to remember Chaisson's caveat above: if it can happen here, then it can happen anywhere, and just because we are unaware of it does not mean it cannot happen, or cannot already have happened (see, e.g., Norris 2000), somewhere else.

Now, as should be fairly clear, SETI is actually looking for other instances of the full Cosmic Evolutionary scenario moving through phases P-BC-T_-indeed, SETI is predicated upon looking for signs of intelligence manifested through the use of technology, whether by signalling (intentionally or not), or perhaps through other occurrences of it (such as engineering projects that are not explicitly designed for signalling but for some other purpose and which we happen to detect incidentally). Indeed, as should also be clear from Eq. (1), the "orthodox" SETI enterprise (as Bradbury, Ćirković \& Dvorsky 2011, put it), as it has been carried out for much of its 60-year history (Dick 2006), has assumed a Cosmic Evolutionary scenario of the more-or-less explicit form 'Cosmos, Planet, Life, Intelligence, Technology', of which 
we-Cosmos, Earth, Life, Humanity - are obviously an example, but one which nonetheless represents only one particular type of cultural evolution (per the Drake term $f$ ), where intelligence acquires, or has the environmental contextual possibility of developing, technological capabilities.

However, it should also be clear that intelligent species could evolve whose own cultural evolution does not extend to the development of high-technology (such as radio telescopes, or other macro-engineering capabilities) and which thereby remains wholly non-technological, i.e., P-B-C (no T). Our Earthly cetaceans, for example, do not have such technology, despite their probable very high intelligence (Herzing 2010); nor do they have the environmental context in which such technology could even be developed, living as they do in the oceans of Earth. Non-terrestrial P-B-C analogues of these creatures could easily exist elsewhere. In recent years the SETI enterprise has begun to change its operational assumptions to allow for wider search strategies to be devised, which in turn allows for consideration of a wider range of potential scenarios of 'contact' - the usual term used for the discovery of extra-terrestrial life, whether intelligent or not (some of which are discussed in Voros 2018).

I should probably also note, in passing, that in contrast to Claudio Maccone (2014), who has suggested that SETI is a part of Big History, it should be clear from the foregoing argument and discussion that I hold the converse view: that Big History is, actually, a part (which is to say, a subset) of SETI.

The field of Astrobiology, by way of comparison, is concerned principally with just the first two phases of the Cosmic Evolutionary scenario, P-B, and current and planned searches are usually predicated upon looking for signs of past or present biological activity ('biosignatures') either on bodies in our Solar System (e.g., Mars, Jupiter's moon Europa, or Saturn's moons Titan and Enceladus), or in the spectral imaging of extra-solar planets ('exoplanets') (see, e.g., DomagalGoldman et al. 2016). The well-known SETI scientist Seth Shostak (2009) has suggested that there is a "three-way horse race to find compelling evidence of life beyond Earth" - two looking for "stupid life" (Astrobiology), and one for intelligence (SETI)which, in his view, is an even-chance split among the three contenders, and will be resolved within a couple of decades or so as our searches widen and search technologies improve. In his public lectures he often likes to bet everyone in the audience a cup of coffee that this will be so (e.g., Shostak 2012, c.7m). For my part, I'd rather have the 'contact' than the coffee!

In short, then, I see Big History as the central standpoint or 'origin' (to use the term both in a quasimathematical sense as well as in resonance with David Christian's sense) from which we can expand our perspective 'outward' to include other multidisciplinary 'sibling' approaches that, in a sense, 'enfold' the Big History viewpoint in successively nested contexts of scale and scope: SETI, Astrobiology, and Cosmic Evolution in its multi-phase conception. Big History, then, as 'our' trajectory through the full multi-phase scenario of Cosmic Evolution, is thereby seen to be just one strand in what, I hope, may be a cosmic tapestry of many other related analogous trajectories experienced by other intelligent entities who have themselves awoken to their own analogue of the Big History narrative and the sense of wonder and even awe it engenders. Perhaps their trajectories will have similar themes, or perhaps they will have some suitably intriguing contrasting counterpoints, that will further reveal the richness and texture possible in the unfolding processes of Cosmic Evolution. We are, as yet, but one voice, singing alone in the Great Cosmic Dark. We long to hear a second, desperately searching for another to sing harmony with, or at least to know that somebody else is out there. Let us hope, with Sagan and Shostak, that it is not too long before another voice in the "cosmic fugue" joins in with ours...

\section{The Frame, part 2 - Inward}

Of course, the 'outward' direction from our customary view of Big History is not the only possible path to 
explore further; there is a second direction that takes us 'inwards', not in terms of smallness or miniaturisation, but rather 'inwards' into our consciousness and 'interiority', as intimated by Jantsch's comments above. Contemplative and meditative traditions have been doing this for thousands of years, of course, but it is only in comparatively recent times that some of their insights have begun to be tested and verified scientifically (e.g., Goleman \& Davidson 2017; Wright 2017), which is of course an entirely non-negotiable entry prerequisite for any research to be considered seriously by the Big History enterprise per the IBHA ("empirical evidence and scholarly methods"). Thus we now turn our attention from exploring 'outer' space and the expanded set of nested contexts which we examined there, to begin to explore the perhaps even more fascinating terrain of 'inner' space, and the insights and findings that we may yet find awaiting us there. And, in order to do this, we are going to need a good map.

\section{The Integral Framework of Ken Wilber}

One of the most comprehensive contemporary models of psychology and consciousness is the 'integral' model or framework developed over several decades of work through five main 'phases' by the American philosopher of consciousness Ken Wilber (1999-2000, 2006, 2007). In 1995, his earlier work elaborating individual psychological and collective sociocultural evolution was integrated and unified with the materialenergetic evolutionary complexity view of Jantsch from SOU (Wilber 1995), just as was suggested to be possible by Jantsch's comments above. Figure 4, adapted from some of Wilber's more recent work (2016), shows some of the details of a part of the overall model. In essence, it re-depicts, elaborates and extends the material-energetic perspective of Jantsch, with microevolution here placed on top and macroevolution on the bottom. Key milestones in those evolutionary processes can be seen represented, and a comparison with Figs 1-3 will show that humans emerge as a distinct stage of complexity at around milestone 9/10 (the numbers on the diagonals represent arbitrary units of increasing complexity, and are used principally for correlative cross-comparison with the corresponding level of complexity in the other branch).

On the upper branch, for example, one can see the usual progression from atoms to molecules to prokaryotes to eukaryotes to multicellular organisms and beyond, with the (proto-)human structure of a triune

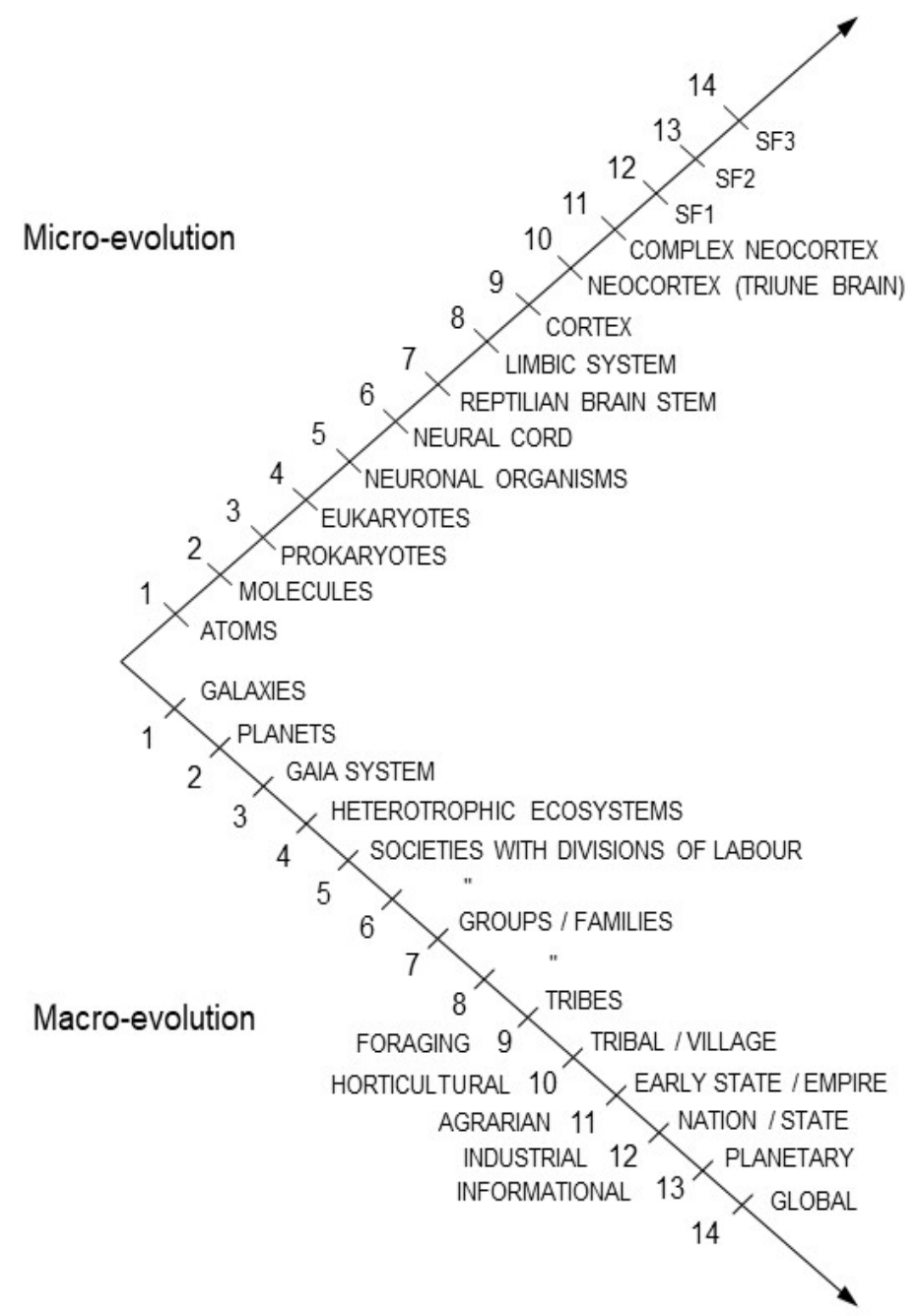

Figure 4: Combination, re-rendering and extension of Figs 1-3, with the positions of micro- and macro-evolution swapped, and with newer more detailed human milestones of complexity elaborated and added. Source: adapted from Wilber (2016, Fig. 3.1, p. 139). 
brain appearing at around milestone/level 10. The corresponding macro-evolutionary sequence can be seen along the bottom: galaxies, planets, Gaia system, heterotrophic ecosystems and so on, up to distinctly human forms of social organisation (e.g., villages, early states, and so on) as well as the well-known historical sequence of forms of techno-economic base for human societies: foraging, horticulture, agrarian, industrial and informational.

Thisfigurealsoimplicitlyshows the threemainphases of 'Cosmic Evolution manifested as Big History', with the origin of the axes ('level 0') representing the Big Bang; the lowest levels of complexity (1 and 2) being the astrophysical/cosmological phase; the next six or seven levels ( 3 to 8 or 9 ) being the biological phase; and the further levels of complexity beyond level $9 / 10$ being the cultural phase. The principal way in which Fig. 4 differs from Fig. 3 is in the elaboration of the individual entities in the later milestones/levels of the upper branch to explicitly designate the informationcarrying and -processing structures found in complex multicellular organisms, and to show their subsequent complexification and cephalisation: neural cords develop into a brain stem which adds a limbic system and a cortex, then a neocortex (triune brain), and then a complex neocortex. The structures designated 'SF1', 'SF2' and 'SF3' are further more complex structures whose presence in the diagram will become clearer with Figure 5. The lower branch also shows an elaboration of Fig. 3 wherein the distinct forms of polity mentioned in the centre of Fig. 3 are explicated and correlated with the techno-economic base.

\section{Consciousness and Interiority}

The large empty gap on the LHS of Figure 4 no doubt alerts the reader to the fact that one can expect to see that side filled-in in a subsequent Figure. This is indeed the case (as a passing glance at Figure 5 shows). The RHS branches of Figure 4 represent (per Jantsch) increasing complexity of material-energetic structural organisation - essentially how matter-energy becomes more complex over time: this is standard Big History.
The arrows on the end of the diagonals are intended to show that this process is continuing, and hint at the correlation between the passage of (cosmological) time and increasing complexity. These RHS branches show empirically-measureable material - in other words, 'physical things' that are subject to measurement, and possess what in metaphysics is called "extension", or what the philosopher Alfred North Whitehead in his process philosophy called "simple location" (cf., e.g., Sherburne 1981; Whitehead 1978). When the corresponding LHS is introduced, however, as in Figure 5-which also shows a few more details of the extended diagram adapted from Wilber (2016) - we see that, in contrast, the complexity on the LHS is not that of material with extension or objects possessing simple location, but of structures of consciousness (and one can indeed see an instance of Whitehead's terminology in the upper left branch, viz "prehension" at level 1).

While Figure 5 may seem a somewhat complicated diagram, it actually represents a considerable simplification of two interrelated aspects of the totality of the full multi-faceted, multi-element model. ${ }^{3}$ Space does not allow a more extended discussion here, but the interested reader may consult Wilber (1995) for a more detailed introduction to this important 'phase 4' elaboration of the integral model, or Wilber (1997) for a briefer and more accessible introductory commentary on the basics of the model. A more extensive and demanding 'phase 5' elaboration can be found in Wilber (2006), while a more popular rendering for general readership can be found in Wilber (2007).

The best way to read Figure 5 is to (somewhat loosely, and certainly not rigidly) correlate the corresponding levels of complexity in one branch with those in another. For example, notice that in the (individual-exterior) upper-right (UR) branch, level 8 of structural complexity ('limbic system') correlates with, in the upper-left (UL) branch, an interior capacity for experiencing 'emotion'. Similarly, at

3 For the information of those who wish to follow this up through the cited references, the two aspects mentioned are Quadrants and Levels. 
level 9, a 'cortex' in the UR correlates with an interior capacity for 'symbols', while at level 10, a 'neocortex' correlates with an interior capacity for 'concepts'. Now, we note that, in the UL, beginning with level 11, the sequence of interior capacities is: rules (equivalent to 'concrete-operational' cognition), formal ('formaloperational' thinking), pluralistic, and 'visionlogic', the last two being Wilber's terms for certain post-formal types of cognition (see, e.g., Commons, Richards \& Armon 1984; Commons \& Ross 2008). These interior capacities are thereby correlated with certain correspondingly more complex structures in the UR: a complex neocortex at level 11, and the further SFn 'structure-functions' of greater structural complexity at higher levels (see, e.g., Wilber 1997). It suffices to say here that the higher levels of complexity of the left and right upper branches of Figure 5 can be

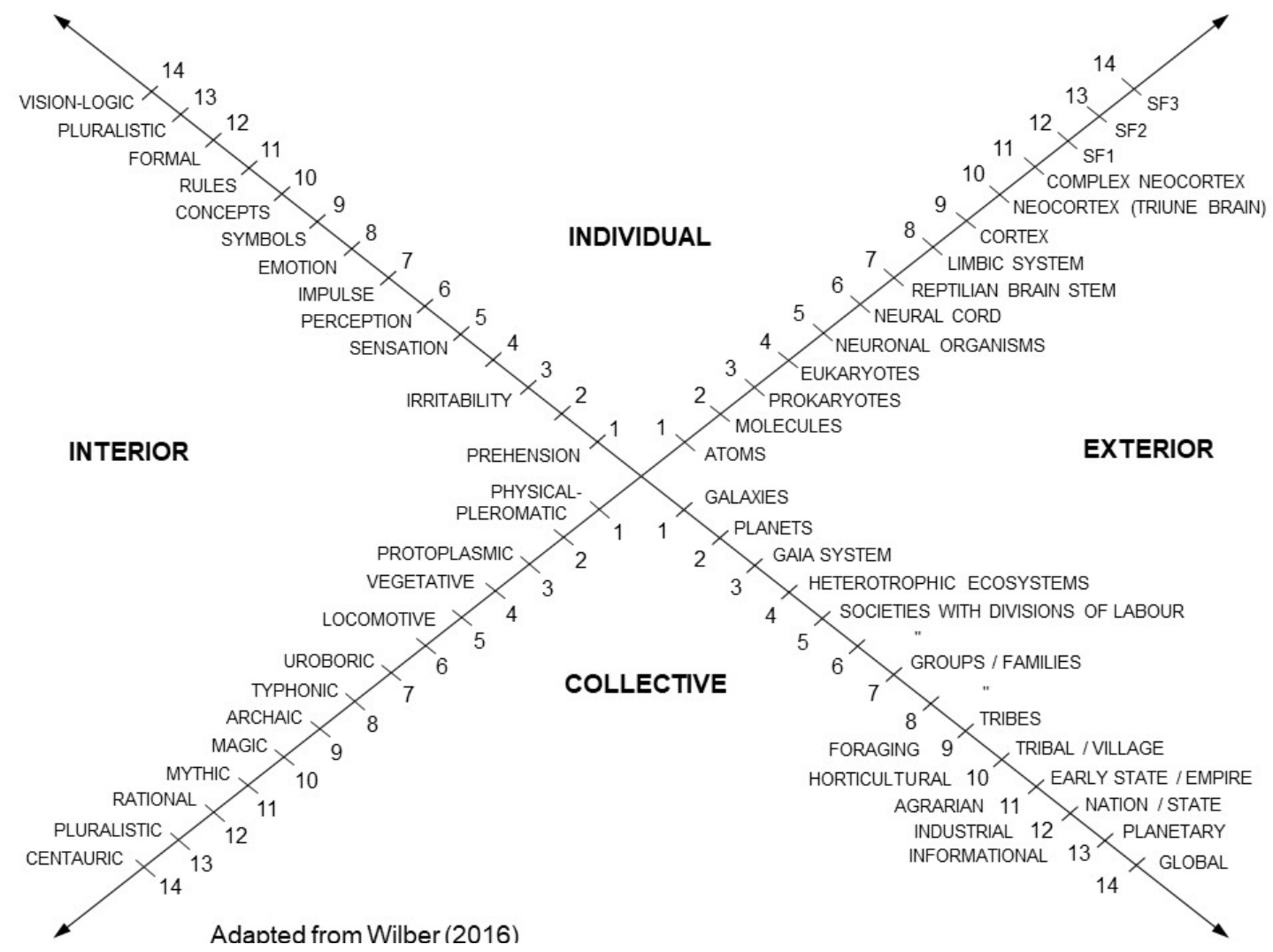

Figure 5: Elaboration of Fig. 4 showing 'interior' experience (interiority) correlated with the corresponding material-energetic 'exteriors' of structural organisation. Source: adapted from Wilber (2016, Fig. 3.1, p. 139). thought of as a representation of two different aspects of individual human consciousness - the 'exterior' material-energetic substrate (i.e., the brain, including the brain stem, limbic system, etc) in the UR, and the 'interior' felt, 'lived experience of being conscious' in the UL, supported by this physical substrate. Or, if you will, the physical-material brain is depicted in the later stages of the UR and the consciously-experienced mind in the later stages of the UL.

To see how the lower branches are best interpreted, it will be necessary to further fill in the diagram with another level of structure; this is shown in Figure 6.

The "Four Quadrants" as shown in Fig. 6 depict four distinct aspects of certain entities existing in the natural world. It is important to note that Wilber regards the main diagram of the "Four Quadrants" as merely "a simple outline" (1997, fn1, p.76), or "reasonable schematic summary" of "over two hundred developmental sequences recognised by various branches of human knowledge", which is most certainly "not intended to be cast in stone" (1997, p. 73). That is, these are somewhat fluid general correlations that should not be regarded as rigidly strict, which would in fact ruin their very utility as what he calls "orienting generalisations". Thus, as noted, the RHS represents objectively measureable 'exterior' attributes, while the LHS similarly represents subjectively interpreted 'interior' 
experience, in both individuals and collectives (upper and lower halves respectively).

The UL thus represents (personal) interiority, or the 'interior of the individual'. Wilber terms this the 'intentional' quadrant as it is where intentions and intentionality reside inside our individual consciousness - thus it is also rendered in the form of the diagram used here (which differs slightly from Wilber's original source version) as 'consciousness'. The UR represents the objectively-measurable attributes of individual entities, which Wilber terms the 'behavioural' quadrant, as this is where empirical observations of entities are made, including the behaviours of those entities or organisms - so it is also rendered here as 'organism' in this form of the diagram (although there are several other forms). ${ }^{4}$ The lowerleft (LL) represents the common aspects of interiority which a collective of individuals mutually share, which Wilber thereby terms the 'cultural' quadrant, as this is where shared beliefs, values, language, mutual understanding and worldviews are found-thus, it is where 'culture' and 'worldviews' reside, which latter is how it is rendered here. The lower-right (LR) represents the objectively measureable aspects of collective social systems, such as forms of activity (e.g., techno-economic base and polity) or forms of organisation, hence Wilber's terminology of the 'social' quadrant, also rendered here as 'organisation'.

The correlations between UR and UL above are

4 The origin of the nomenclature "behavioural" for the UR comes from a version of the Quadrant diagram that does not show explicit levels, but simply notes the general type of perspective epitomised by each 'quadrant view'. The 'UR quadrant view' derives from approaches to consciousness that are based on observing those objectively physically-measureable aspects of an individual that possess ('exterior') simple location, such as height, weight, brainwave patterns, neurotransmitter concentrations, bodily movements, etc (as opposed to the lived subjective experience of consciousness: the UL). In this quadrant's perspective, therefore, 'consciousness' is viewed in wholly biological and neurophysiological terms, and so consciousness as such is essentially just a neurological system. If you focus on examining just the empirically-measurable aspects and behaviours of the organism, you thus have essentially a Skinnerian 'behaviourist' view of the entity. Whence the terminology. now extended to the LR and LL, so that, e.g., level 12 formal cognition in the UL correlates to a rational worldview in the LL and with an associated industrial techno-economic base and nation-state form of polity in the LR. Similarly, level 11 rules-based cognition correlates to a mythic worldview, and an agrarian techno-economic base and early state/empire polity, and so on. In this view, evolution 'unfolds' in all four quadrants simultaneously - on the RHS by way of the familiar macro/micro processes which Jantsch described; on the LHS through analogous mutuallydependent micro/macro processes of psychology with enculturation; as well as across and between both the left hand and right hand sides in concert. Wilber's frequent term for this four-fold interdependent unfolding is "tetra-evolution". Taking some time to carefully study the approximate correlations at each level to see how they 'mesh' across the quadrants will reward the reader with further insight into how the process of Cosmic Evolution has played out in this corner of the universe here on planet Earth. Here then is complexity-based Big History with consciousness added - a unified model of what Jantsch's comments above foreshadowed as a "formulation of the relations between biological / ecological / sociobiological evolution on the one hand and psychological/ sociocultural evolution on the other" - here literally with the former on the RHS and the latter on the LHS. After nearly two-and-a-half decades of familiarity with it, I still find this compelling mutually-interdependent "tetra-evolutionary" perspective to be a gift that just keeps right on giving...

\section{'Meaning' in Big History?}

The main utility of Figure 6 for our purposes here is that it shows how customarily-understood Big History, comprising the rise of material-energetic complexity over time (i.e., the RHS, per Jantsch and others) is included as but one-half of an even broader representation of this process that also incorporates human conscious experience and interiority (i.e., the LHS). ${ }^{5}$ This is important, because it provides one

\footnotetext{
5 In fact, this was one of the three presentations I made at
} 


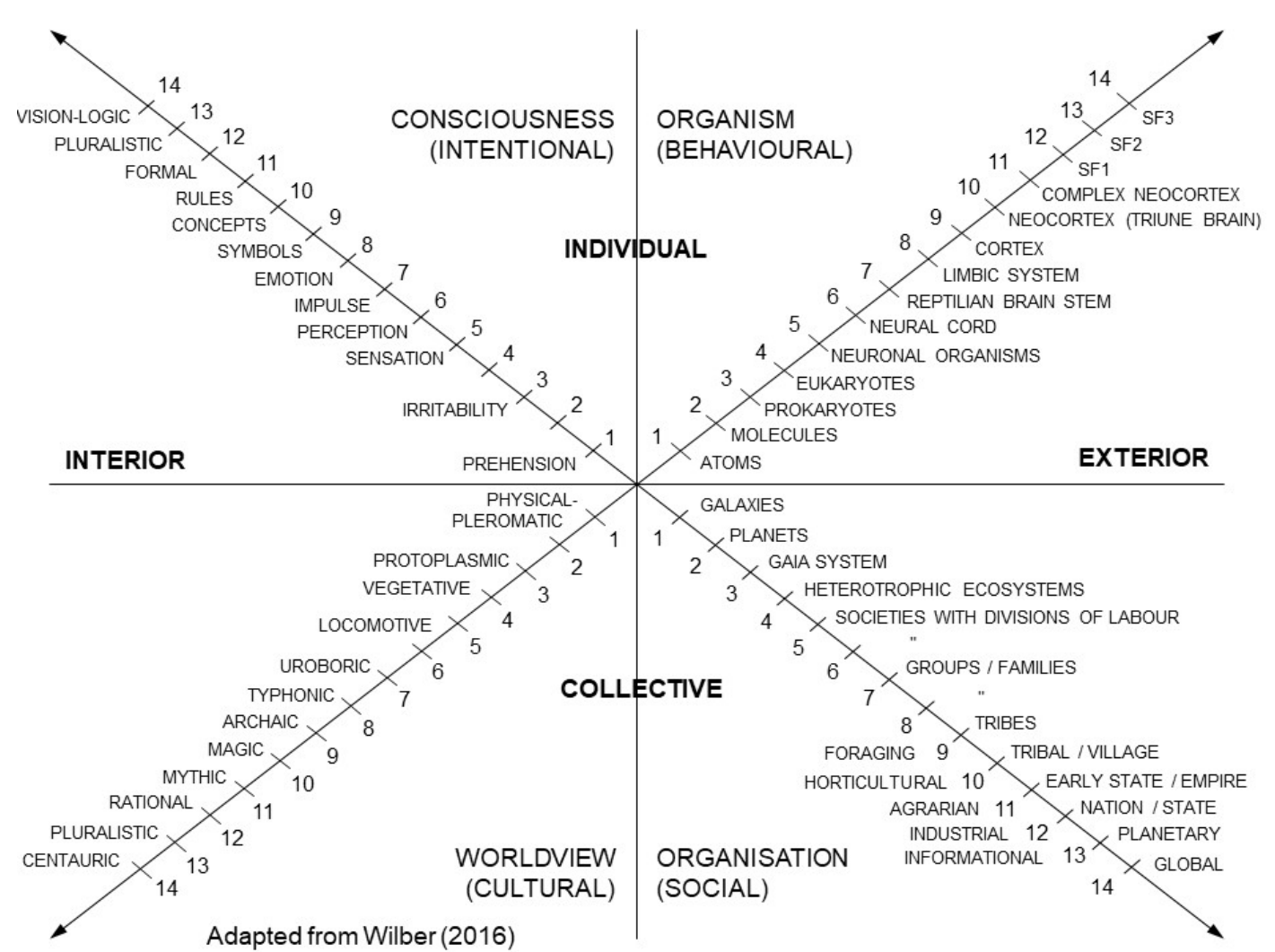

Figure 6: Further elaboration of Fig. 5, showing the two-fold divisions of an 'interior' and 'exterior' for each of both individuals and collectives. Source: adapted from Wilber (2016, Fig. 3.1, p. 139), although see also Wilber (1997) for a useful and quite accessible introductory commentary on these how these "Four Quadrants" are best viewed as a preliminary "reasonable schematic summary" of "over 200 developmental sequences recognised by various branches of human knowledge" (p.73).

and perhaps to even feel moved to seek to read a more-or-less quasi-religious or even spiritual dimension onto it, as some have done (e.g., Abrams \& Primack 2011; Christopher 2013; Genet et al. 2009; Primack \& Abrams 2006; Swimme \& Tucker 2011), it should nonetheless be very clear that these sensibilities reside solely within us-i.e., they exist at all in the Universe simply because we do, as children of the Universe.

In other words, meaning 'exists' 'in' Big History as part of the human dimension of conscious interiority, which latter

pathway that may help resolve the contentious issue of whether, and if so where, 'meaning' might reside in Big History. If Big History is - as I have suggested and argued at length in this article - the story of us and how we came about through the (more general, nomothetic) processes of Cosmic Evolution, then the answer is, in this view, very clear and quite simple: any meaning there may be in Big History resides in us, as part of our own interior consciousness, both as individuals and as shared with each other through our collective worldviews.

Thus, while it is perfectly legitimate for people to feel a sense of awe and wonder at the astounding beauty of the Cosmos (I mean, who wouldn't, right?!), the inaugural IBHA conference in Grand Rapids in August 2012 (Voros 2012). is an outcome of the unfolding of the (four-fold, per Jantsch/Wilber) Cosmic-Evolutionary processes that have given rise both to our species as well as to the associated interiority of our species.

As a consequence of this expanded 'complexityplus-consciousness' perspective, then, it transpires that the only way that 'meaning' as such could exist 'out there' beyond ourselves would be if it existed in the consciousness and interiority of other sentient beings elsewhere. Anyone else out there in the wider Universe possessing sufficiently-complex interiority and sufficiently-advanced cultural evolution would therefore be another instance or version of the playingout of the multi-phase Cosmic-Evolutionary scenario, and thus, almost of necessity, would potentially also have their own analogue of Big History. In other 
words, in this view, meaning requires conscious interiority to contain it, and so, wherever conscious interiority exists, there too could 'meaning' potentially also exist.

Seen in this light, then, perhaps our search for life and intelligence elsewhere in the Universe (and thus for the interiority any such intelligence may possess) might just conceivably be motivated by a subconscious and ineffable search for

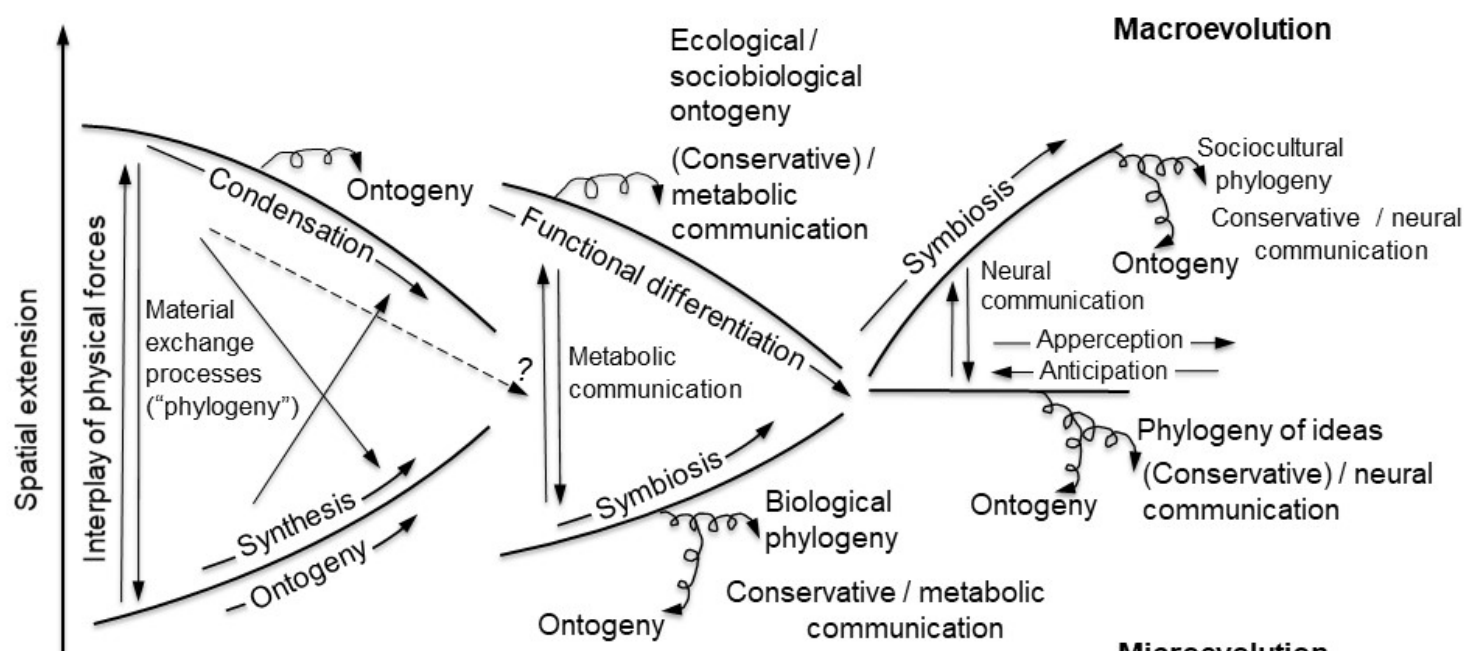

Microevolution

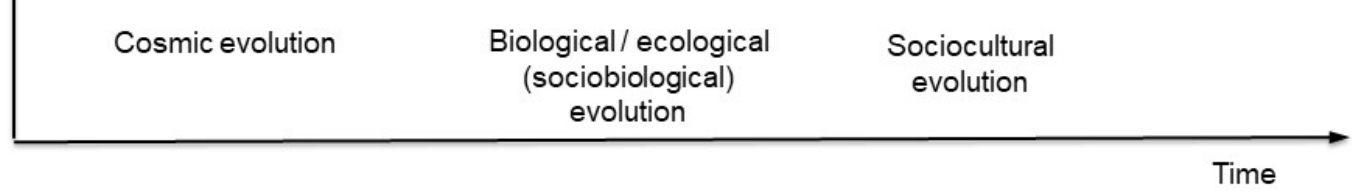

Figure 7: "The evolving role of communication in the three major phases of evolution." Source: Recreated by the author from Jantsch (1980, Fig 40, p. 208.) a deeper and more profound sense of meaning-not merely that which we make for ourselves, but also one that might be brought about by meeting other distinct minds with which we might compare notes and which might also share a similar common sense of wonder and awe, as some of us here on Earth do, of even existing at all... Perhaps we are simply searching for the cognitive companionship of any far-flung cosmic-evolutionary siblings that might exist out there among the stars...

\section{Onward - The Future}

The Jantsch-Wilber integrated model as presented above also allows us to consider a third direction of inquiry and exploration which is distinct from the 'outward' and 'inward' directions we have heretofore examined and surveyed: namely, the 'onward' direction of what future(s) may be in prospect, as the dual or "four-fold" unfolding of material complexity and interior consciousness continues through time.
There are at least two ways that the future can enter in this view; one explicit, the other implicit.

Figure 7 shows another elaboration of Jantsch's formulation of the three main phases of universal coevolution, this one dealing with the evolving role of communication, which implies an evolution in the processes yielding or governing flows of information. ${ }^{6}$ Notably, one sees - with the arising of sociocultural evolution and neural communication in the third phase - the appearance of the dual capacities of 'apperception' and 'anticipation' with explicit and distinct directions of flow in time. These can, for our purposes here, be roughly understood as capacities for intercepting and interpreting information about the past and present (apperception), as well as about alternative potential futures (anticipation). In other words, with the arising of Humanity in the Big History sequence 'Cosmos, Earth, Life, Humanity', the Universe (through us) became able to not only

6 Indeed, information flows feature very prominently in SOU. Our brief comments here have not really adequately highlighted or done justice to the extent to which this is so. 
perceive and understand the/its entire past - and thus the processes by which this capacity itself emerged through that very sequence-but also to imagine and anticipate the potential futures that may yet lie ahead.

Thus it happens that The Future enters Cosmic Evolution as an object of explicit awareness with the arising and emergence of sufficiently-complex interiority (although note that there are multiple degrees of complexity involved in the emergence of this capacity; see Hayward 2008). And, therefore, this new capacity allows for (as it were) 'course corrections' in the overall direction/s of the trajectory/ ies of sociocultural evolution, a capability in which Jantsch was also very interested owing to what he perceived as the increasingly-urgent and especially vital necessity for it (Jantsch 1972b, 1975). Thus we need (both as individuals and as a species) to develop our capacity for anticipation and foresight as an explicit and deliberate competence in order to ensure not only humane and just futures for members of our own (and other) species, but also to ensure the coming-about of futures that will even include us at all (Miller 2018; Slaughter 2004, 2006). It is a quite sobering thought that, with the emergence of sociocultural evolution on Earth, there has also arisen the technological capability to end the three-phase process of Cosmic Evolution on this planet through either our gross negligence or abject stupidity, let alone for it to occur through sheer bad luck (Peter et al. 2004). Let us hope that our emergent capacity for anticipation allows us to chart a course through the dangerous rapids of the oncoming future with the skill and deftness required to navigate them safely and well.

The future also enters implicitly by way of what the arrows on the axes of Figs 4-6 hint at. The highest level/milestone of complexity shown in the various forms of the Four Quadrants, level 14, represents the current highest level of complexity of very wellelaborated structures for which a broad consensus view exists among the majority of scholars and researchers working in the respective fields drawn upon to create the ("reasonable schematic summary") quadrant diagram. Wilber's own earlier work on the LL and in particular UL quadrants shows, however, that there are several meditative and contemplative traditions which describe general contours of even more complex and subtle interior capacities than have been studied in traditional psychological research, and which have conventionally been considered the province of transpersonal psychology (see, e.g., Wilber 1996a, 1996b; Wilber, Engler \& Brown 1986, and a more recent and highly detailed description in Wilber 2017).

These capacities are not necessarily paranormalalthough the language used to describe them can be fairly opaque and often rather difficult to interpret in an unambiguous way, which can lead to this type of reading or interpretation of them. As well, the frequent $1^{\text {st }}$-person decidedly subjective descriptions given can be somewhat difficult to test and verify through correlation with the empirical results of standard $3^{\text {rd }}$-person UR objective methods, so this is a quite challenging and potentially fraught arena of research (e.g., see the individuals discussed in chapter 11 of Wright 2017). Nonetheless, even an arch-sceptic such as the cognitive neuroscientist and podcaster Sam Harris can be found concerning himself with studying the neurological (i.e., UR) basis of meditation, and offering what he calls a "spirituality without religion" based on a thoroughly secular view of some of these traditions' meditative practices (Harris 2014). The evidence for these capacities is obviously considerably sparser than for the more well-known ones detailed in the UL of Figure 6, although the claims of some traditions which foreground various forms of meditation (including mindfulness) have in recent years increasingly been investigated and tested, with some quite suggestive early results (e.g., Goleman \& Davidson 2017; Wright 2017). These preliminary results intimate that, at the very least and if nothing else, prima facie the claims made for the existence of more complex and subtle cognitive capacities merit closer examination, and may be useful as guiding hypotheses for further more detailed and more 
extensive research.

Individuals possessing these capacities are exceedingly rare, so they obviously do not appear in the diagrams representing the widespread 'broad consensus' of a majority of scholars which have been presented here, owing to the difficulties (and controversies) of verification in very small sample sizes and populations (e.g., some two-dozen or so in some of the work reported in Goleman \& Davidson 2017). Nonetheless, they can be taken as tentative hypotheses of what potential future human-evolutionary capacities may increasingly become - in much the same way that, while formal-operational thinking was once exceedingly rare long ago, it is now considered the standard level of cognitive capacity that adolescent children are expected to attain at school. Thus, in the rising tide of evolutionary complexification, what was once rare and fleeting may eventually become widespread and commonplace.

This suggests that, as newer and more complex capacities emerge with greater frequency in the UL, and, as the individuals who possess these capacities find each other and come together, so newer collectively-shared worldviews will emerge in the LL, which will then potentially give rise to newer forms of social organisation and social structures in the LR. The cross-comparative correlations between the respective levels of complexity already shown in the Quadrants of Fig. 6 would then simply move up/out another level as these capacities and structures begin to crystallise and spread, thereby elaborating yet another milestone in the four-quadrant evolutionary view of Big History depicted there.

Therefore, continuing to study the as-yet sparselycharted possibilities of the hinted-at higher human potentials may conceivably give us insights into possible future human cultural and social forms, including newer values, philosophies, technoeconomic systems and political structures. This is potentially an enormously rich source of exceedingly interesting lines of possible inquiry to pursue, which may even give us some grounds for some qualified measure of rational hope that (with due care and a bit of luck) Cosmic Evolution on this planet may yet continue to unfold its remarkable story for some considerable period of time to come...

In closing this brief discussion of the application of the integral model to the future, I'd like to note, in this regard, that Jantsch himself remarked (1981b, p. 213) - in what appear to be his very last words in print, apropos this emerging 'evolutionary vision' of the cosmic evolutionary processes which gave rise to us - that:

The evolutionary vision is itself a manifestation of evolution. The reward for its elaboration will not only be a new (or partly revived) natural philosophy or an improved academic understanding of how we are interconnected with evolutionary dynamics at all levels, but also an immensely practical philosophy to guide us in a time of creative instability and major restructuration of the human world ... . With such an orientation, science will also become more realistic and meaningful for the concerns of human life. It will be not merely an end product of human creativity, but a key to its further unfolding in all domains. (emphasis added here)

\section{Concluding Remarks}

This paper sought to extend the customary increasing material-energetic complexity-based perspective of Big History in two main ways - firstly, 'outward', in the direction of 'outer space'; and secondly, 'inward', in the direction of 'inner space' (i.e., conscious interiority) - taking Erich Jantsch's pioneering work as our principal frame of reference and point of origin. Part of the motivation for this two-fold approach was to examine whether and how the (somewhat vexed) question of 'meaning' in Big History might be fruitfully tackled.

In the 'outward' direction, we sought to 'situate' Big History as part of a broader nested set of related 'sibling' multi-disciplines-SETI, Astrobiology, and Cosmic Evolution. We saw therefore how Big History 
can thereby be viewed as simply 'our' instance of the unfolding of the more general universal multiphase process of Cosmic Evolution, an unfolding process that may perhaps have occurred at other places and times elsewhere. This 'situating' of Big History in such an expanded 'cosmic' setting was done in the hope of encouraging the building of closer ties between the respective agendas of all of these knowledge fields by highlighting some of their similarities, and was intended as a contribution to broadening the growing awareness of shared interests that are becoming increasingly recognisable as Big History becomes more mainstream and begins to forge stronger connections and alliances with similarly multidisciplinary endeavours, such as Astrobiology (see, e.g., Crawford 2018), SETI, and, of course, Futures Studies. ${ }^{7}$

In the 'inward' direction, we sought to extend our frame of reference-along lines Jantsch himself intimated but was never able to fully attempt or ever complete-by examining how human consciousness and 'interiority' itself might also be included and integrated into the prevailing material-energetic complexity-based perspective in a natural way. The 'integral model' of Ken Wilber was then introduced and briefly discussed in outline as one possible such extension, by showing how and where some key features from Jantsch's work exist and are incorporated within the general framework. We saw then that the distinct perspectives of increasing material-energetic complexity, and of increasing complexity of consciousness and interiority, are but two 'half-views' of a more integrated whole view, both of which are needed for the full appreciation of the bigger picture. In this way, we sought to introduce a workable extended perspective on Big History; one which includes both the customary view of increasing

7 As evidenced, for example, by the (at the time of writing, upcoming) International Symposium on Life in the Universe 2019: Big History, SETI and the Future of Humankind, to be held in the Republic of San Marino (Italy) in July 2019. https://bighistory.org/2019-life-in-the-universe-conferenceinformation/ material-energetic complexity, as well as formally recognising and incorporating the undeniable fact of our own conscious existence ("cogito ergo sum") as an inseparable integral part of the very structure and fabric of Big History itself.

We saw from this more-expanded framing perspective, therefore, that 'meaning' requires and subsists within (human) conscious interiority, so that any meaning that may exist in Big History does so precisely through the very fact of our own conscious existence, via the subjective human dimension of Big History, and not objectively beyond it. However, we also noted that any other instances of the playing-out of the full Cosmic-Evolutionary scenario would likely also give rise to other sentient beings with their own conscious interiority, who accordingly might perhaps have their own analogue of the Big History perspective and their own attendant forms of meaning-making, all of which would be enormously interesting to compare notes with. It was suggested that, since such 'meaning' would be outside of us in a very literal sense, perhaps SETI has been and is motivated by a subconscious search for the deeper meaning that finding and/or connecting with other cognitive beings 'out there' would represent.

Finally, we examined how the expanded framing perspective could be used to consider the 'onward' direction of 'the future', and we saw how the future can enter the frame in both an explicit (per Jantsch) and implicit (per Wilber) form. In its explicit form, we saw how the arising in us of sufficiently-complex conscious interiority brought with it the dual capacities to intercept information about the past and present (apperception) as well as about potential futures (anticipation), and we noted the increasing urgency of more fully developing this latter capacity for the sake of guiding our further cultural evolution more wisely than we have hitherto done, lest that process come to a rather unnecessary and pointless end. In its implicit form, we saw that the potentials latent in the "farther reaches of human nature"-implied by the very uppermost extents of individual interiority which have 
so far been only very partially and sparsely-mappedhint at newer and more expanded cognitive capacities, as well as their attendant cultural worldviews and forms of social organisation. Studying the contours implied by this emerging domain of human experience may give us deeper insights and valuable clues into what and who we may yet become, as individuals and as a species, in the future which is ever-unfolding ahead of us.

We ended with a final word from Jantsch himself who foresaw that this 'evolutionary vision' would not only allow for an improved academic understanding of our deep connection to all levels of the unfolding processes of cosmic evolution (something we in the IBHA have been strongly drawn to as part of our mission), but also that it might perhaps become a useful and practical guiding philosophy that could help us navigate our way through the coming period of increasing instability and re-structuring of human civilisation itself which now, even more, lies so clearly in prospect.

I'd like to finish by dedicating this paper to the memory of Erich Janstch (1929-1980) and the work he undertook. A comment from his contemporary and colleague Milan Zeleny (1981, p. 120) suffices to make the point as clearly as can be:

$[\mathrm{H}]$ is ideas will be missed with an increasing intensity. He will be re-discovered, recognized, and acknowledged as one of the most original systems thinkers of recent decades.

Indeed. Erich Jantsch would have just turned 90, as I write these words in January 2019. One wonders what other incalculable treasures and profound insights we might also have received from him, had it indeed been so...

I sometimes like to imagine that Jantsch would have approved of our current efforts to share ever more widely this dawning awareness of the astonishing storyline of Big History - the evolutionary vision of how the processes of cosmic evolution played out in this corner of the Universe here on planet Earth, allowing the Cosmos (as Carl Sagan put it) "to know itself" - and that we are doing at least some justice to the deeply humanistic sentiment and fond hope he expressed in what turned out, so sadly, to be his final words to us.

Let us take up the torch of the evolutionary vision that he so brilliantly lit for us, and carry it forward with due care and responsibility, to light the way ahead for the benefit of all sentient beings who live on this planet at this point in its (big) history, as well as for all those who are yet to come after us, as cosmic evolution itself continues to unfold...

\section{References}

Abrams, NE and Primack, JR 2011, The new universe and the human future: how a shared cosmology could transform the world, Kindle edn, Yale University Press, New Haven, CT.

Aunger, R 2007, 'Major transitions in 'big' history', Technological Forecasting and Social Change, vol. 74, no. 8, Oct, pp. 1137-1163. doi:10.1016/j. techfore.2007.01.006.

Bradbury, RJ, Ćirković, MM and Dvorsky, G 2011, 'Dysonian approach to SETI: a fruitful middle ground?', Journal of the British Interplanetary Society, vol. 64, no. 5, May, pp. 156-165.

Brown, CS 2008, Big history: from the big bang to the present, New Press, New York. Originally published 2007.

2017, Big History, small world: from the Big Bang to you, Berkshire Publishing Group, Great Barrington, Massachusetts, USA.

Capra, F 1981, 'Erich Jantsch 1929-1980', Futures, vol. 13, no. 2, Apr, pp. 150-151. doi:10.1016/00163287(81)90022-7.

Chaisson, EJ 1979, 'Cosmic evolution: a synthesis of matter and life', Zygon, vol. 14, no. 1, Mar, pp. 23-39. (Reprinted from Harvard Magazine, Nov-Dec 1977, pp. 21-33.). doi:10.1111/j.1467-9744.1979.tb00344.x 
2001, Cosmic evolution: the rise of complexity in nature, Harvard University Press.

2007, Epic of evolution: seven ages of the cosmos, new paperback edn, Columbia University Press, New York. Originally published Dec 2005.

2008, 'Cosmic evolution: from the big bang to humankind', Interactive web pages, Harvard University, https://www.cfa.harvard.edu/ ejchaisson/ cosmic evolution/.

2014, 'The natural science underlying Big History', The Scientific World Journal, vol. 2014, p. 41. doi:10.1155/2014/384912.

Christian, D 2004, Maps of time: an introduction to big history, University of California Press, Berkeley.

2008, Big history: the big bang, life on earth, and the rise of humanity [audiovisual material], 48 lectures, 30 mins/lecture, The Great Courses, course no. 8050, The Teaching Company, Chantilly, Virginia, USA. http://www.thegreatcourses.com/.

2018, Origin story: a Big History of everything, Little, Brown and Co., New York.

Christian, D, Brown, CS and Benjamin, C 2013, Big history: between nothing and everything, McGraw-Hill Education, Boston.

Christopher, D 2013, The holy universe: a new story of creation for the heart, soul and spirit, New Story Press, Santa Rosa, CA, USA.

Chyba, CF and Hand, KP 2005, 'Astrobiology: the study of the living universe', Annual Review of Astronomy and Astrophysics, vol. 43, no. 1, Sep, pp. 31-74. doi:10.1146/ annurev.astro.43.051804.102202.

Commons, ML, Richards, FA and Armon, C (eds) 1984, Beyond formal operations: late adolescent and adult cognitive development, Praeger Pubs., Westport, CT, USA.

Commons, ML and Ross, SN 2008, 'What postformal thought is, and why it matters', World Futures, vol. 64, no. 5-7, Jul, pp. 321-329. Issue: 'Postformal Thought and Hierarchical Complexity', ML Commons \& SN Ross (eds). doi:10.1080/02604020802301139
Crawford, IA 2018, 'Widening perspectives: the intellectual and social benefits of astrobiology (regardless of whether extraterrestrial life is discovered or not)', International Journal of Astrobiology, vol. 17, no. 1, Jan, pp. 57-60. doi:10.1017/s1473550417000088

Delsemme, A 1998, Our cosmic origins: from the Big Bang to the emergence of life and intelligence, Cambridge University Press.

Dick, SJ 2003, 'Cultural evolution, the postbiological universe and SETI', International Journal of Astrobiology, vol. 2, no. 1, Jan, pp. 65-74. doi:10.1017/ S147355040300137X.

2006, 'Anthropology and the search for extraterrestrial intelligence: an historical view', Anthropology Today, vol. 22, no. 2, Apr, pp. 3-7. doi:10.1111/j.1467-8322.2006.00421.x.

2009, 'Cosmic evolution: history, culture and human destiny', in SJ Dick \& M Lupisella (eds), Cosmos and culture: Cultural evolution in a cosmic context, NASA Special Publication, vol. SP-20094802, National Aeronautics and Space Administration, Washington, DC, Chap. 2, pp. 25-59.

Domagal-Goldman, SD, Wright, KE, Adamala, K, Arina de la Rubia, L, Bond, J, Dartnell, LR, Goldman, AD, Lynch, K, et al. 2016, 'The astrobiology primer v2.0', Astrobiology, vol. 16, no. 8, Aug, pp. 561-653. doi:10.1089/ast.2015.1460.

Drake, FD 1961, 'Discussion at Space Sciences board'. Presented at National Academy of Sciences Conference on Extraterrestrial Intelligent Life, Green Bank, West Virginia, USA, November 1961.

Ekers, RD, Cullers, DK, Billingham, J and Scheffer, LK (eds) 2002, SETI 2020: a roadmap for the search for extraterrestrial intelligence, SETI Institute, Mountain View, CA, USA. Foreword by Philip Morrison.

Genet, C, Genet, R, Swimme, B, Palmer, L and Gibler, L (eds) 2009, The evolutionary epic: science's story and humanity's response, Collins Foundation Press, Santa Margarita, CA, USA. Foreword by David Christian.

Goleman, D and Davidson, RJ 2017, The science of meditation: how to change your brain, mind and body, 
Penguin Life, London. Published in the USA as Altered traits: Science reveals how meditation changes your mind, brain, and body, Penguin Random House, New York. Also available as Kindle and Audible editions.

Grinin, LE, Carneiro, RL, Korotayev, AV and Spier, F (eds) 2011, Evolution: cosmic, biological, and social, Evolution, vol. 1, Uchitel Publishing House, Volgograd.

Gustafson, L, Álvarez, W, Benjamin, C, Brown, C, Christian, D, Rodrigue, B, Spier, F and Voros, J 2014, 'A Closing Discussion with Big Historians', Closing plenary panel discussion at Teaching and Researching Big History: Big Picture, Big Questions; The 2nd International Big History Association conference, Dominican University of California, San Rafael, California, Aug 6-10. Described as part of the conference report in the IBHA member newsletter: Origins vol. 4, no. 10, 2014, pp.2021. https://bighistory.org/members/origins-bulletin/.

Harris, S 2014, Waking up: a guide to spirituality without religion, Simon and Schuster, New York.

Harrison, AA 2009, 'The future of SETI: finite effort or search without end?', Futures, vol. 41, no. 8, Oct, pp. 554-561. Issue: 'Space: The final frontier', WS Bainbridge (ed.). doi:10.1016/j.futures.2009.04.016.

Hawking, SW and Mlodinaw, L 2010, The grand design, Kindle edn, Random House/Bantam, London.

Hayward, P 2008, Developing wisdom: how foresight develops in individuals and groups, VDM Verlag Dr Müller, Saarbrücken.

Herzing, DL 2010, 'SETI meets a social intelligence: dolphins as a model for real-time interaction and communication with a sentient species', Acta Astronautica, vol. 67, no. 11-12, Dec, pp. 1451-1454. Issue: 'Special Issue on Searching for Life Signatures', JR Elliott (ed.). doi:10.1016/j.actaastro.2010.01.015.

International Big History Association 2016, 'What is Big History?', web page, https://bighistory.org/ whatisbighistory/.

Jantsch, E 1967, Technological forecasting in perspective, Organisation for Economic Co-operation and Development (OECD), Paris. Subtitle: a framework for technological forecasting, its techniques and organisation.

1969a, 'Integrative planning of society and technology: the emerging role of the university', Futures, vol. 1, no. 3, Mar, pp. 185-190. doi:10.1016/00163287(69)90021-4.

(ed.) 1969b, Perspectives of planning, Organisation for Economic Co-operation and Development (OECD), Paris. Proceedings of the OECD Working Symposium on Long-Range Forecasting and Planning, Bellagio, Italy 27 th Oct - 2nd Nov 1968 . .

1972a, 'Forecasting and the systems approach: a critical survey', Policy Sciences, vol. 3, no. 4, Dec, pp. 475-498. doi:10.1007/BF01405349.

1972b, Technological planning and social futures, Cassell, London.

1975, Design for evolution: self-organization and planning in the life of human systems, International library of systems theory and philosophy, George Braziller, New York.

1980, The self-organizing universe: scientific and human implications of the emerging paradigm of evolution, Pergamon Press, New York.

1981a, 'Autopoiesis: a central aspect of dissipative self-organization', in M Zeleny (ed.) Autopoiesis: A theory of living organization, Elsevier-North Holland, New York, pp. 65-88.

(ed.) 1981b, The evolutionary vision: toward a unifying paradigm of physical, biological and sociocultural evolution, American Association for the Advancement of Science selected symposium, vol. 61, Westview Press (for AAAS), Boulder, CO, USA.

Jantsch, E and Waddington, CH (eds) 1976, Evolution and consciousness: human systems in transition, AddisonWesley, Reading, MA, USA.

Linstone, HA, Maruyama, M and Kaje, R 1981, 'Erich Jantsch 1929-1980', Technological Forecasting and Social Change, vol. 19, no. 1, Feb, pp. 1-5. doi:10.1016/0040-1625(81)90045-7.

Maccone, C 2010, 'The statistical Drake equation', Acta Astronautica, vol. 67, no. 11-12, Dec, pp. 1366-1383. 
Issue: 'Special Issue on Searching for Life Signatures', JR Elliott (ed.). doi:10.1016/j.actaastro.2010.05.003

2014, 'SETI as a part of Big History', Acta Astronautica, vol. 101, Aug-Sep, pp. 67-80. doi:10.1016/j.actaastro.2014.02.010.

Miller, R (ed.) 2018, Transforming the future: anticipation in the 21st century, Routledge, London.

Mix, LJ, Armstrong, JC, Mandell, AM, Mosier, AC, Raymond, J, Raymond, SN, Stewart, FJ, von Braun, $\mathrm{K}$, et al. 2006, 'The astrobiology primer: an outline of general knowledge-version 1, 2006' [Education paper], Astrobiology, vol. 6, no. 5, Oct, pp. 735-813. doi:10.1089/ast.2006.6.735.

Morrison, P, Billingham, J and Wolfe, JH (eds) 1979, The search for extraterrestrial intelligence, Dover Pubs., New York.

Norris, RP 2000, 'How old is ET?', Acta Astronautica, vol. 47, no. 2-9, Jul-Dec, pp. 731-733. Issue: 'Space an integral part of the information age', R Monti (ed.). doi:10.1016/S0094-5765(00)00110-7.

Peter, N, Barton, A, Robinson, D and Marc Salotti, J 2004, 'Charting response options for threatening near-Earth objects', Acta Astronautica, vol. 55, no. 3-9, AugNov, pp. 325-334. Issue Title: New Opportunities for Space. Selected Proceedings of the 54th International Astronautical Federation Congress. doi:10.1016/j. actaastro.2004.05.031.

Primack, JR and Abrams, NE 2006, The view from the center of the universe: discovering our extraordinary place in the cosmos, Riverhead (Penguin), New York.

Sagan, C 1980, Cosmos, Illustrated (First) edn, Random House, New York.

1995, Pale blue dot: a vision of the human future in space, Headline, London.

Sherburne, DW (ed.) 1981, A key to Whitehead's Process and Reality, 4th reprint edn, University of Chicago Press, Chicago.

Shklovskii, IS and Sagan, C 1966, Intelligent life in the universe, Holden-Day, Inc., San Francisco. Some versions have Sagan listed as the first author.
Shostak, S 2009, 'When will we find the extraterrestrials?', Engineering \& Science, vol. 72, no. 1, Spring, pp. 1221.

2012, ET is (probably) out there-get ready [TED Talk], TED.com, TEDxSanJoseCA, San Jose, California, April 2012. https://www.ted.com/talks/seth shostak et is probably out there get ready.

Slaughter, RA 2004, Futures beyond dystopia: creating social foresight, Futures in education, no. 5, RoutledgeFalmer, London.

2006, Pathways and impediments to social foresight, vol. 10, Australian Foresight Institute monograph series, Swinburne Press, Hawthorn, Victoria, Australia. Final in the series.

Spier, F 1996, The structure of big history: from the big bang until today, Amsterdam University Press.

2010, Big history and the future of humanity, Wiley-Blackwell, Chichester, UK.

2015, Big history and the future of humanity, 2nd edn, Wiley-Blackwell, Chichester, UK.

Swimme, BT and Tucker, ME 2011, Journey of the universe, Kindle edn, Yale University Press, New Haven.

Tarter, JC 2001, 'The search for extraterrestrial intelligence (SETI)', Annual Review of Astronomy and Astrophysics, vol. 39, no. 1, Sep, pp. 511-548. doi:10.1146/annurev. astro.39.1.511.

2004, 'Astrobiology and SETI', New Astronomy Reviews, vol. 48, no. 11-12, Dec, pp. 1543-1549. Issue Title: Science with the Square Kilometre Array. doi:10.1016/j.newar.2004.09.019.

Tarter, JC, Agrawal, A, Ackermann, R, Backus, P, Blair, SK, Bradford, MT, Harp, GR, Jordan, J, et al. 2010, 'SETI turns 50: five decades of progress in the search for extraterrestrial intelligence', at Proceedings of SPIE7819, Instruments, Methods, and Missions for Astrobiology XIII, RB Hoover, GV Levin, AY Rozanov \& PCW Davies, San Diego, CA, September 7, SPIE - The International Society for Optical Engineering, 781902 . 
Voros, J 2012, 'Complexity + consciousness: a model of Big History based on self-organising complexity, incorporating consciousness'. Presented at Teaching and Researching Big History: Exploring a new scholarly field; the International Big History Association inaugural conference, Grand Valley State University, Grand Rapids, Michigan, Aug 2-5. http://hdl.handle. net/1959.3/229485.

2017, 'Big Futures: macrohistorical perspectives on the future of humankind', in B Rodrigue, L Grinin \& A Korotayev (eds), The way that Big History works: Cosmos, life, society and our future, From Big Bang to galactic civilizations: A Big History anthology, vol. III, Primus Books, Delhi, Chap. 22, pp. 403-436.

2018, 'On a morphology of contact scenario space', Technological Forecasting and Social Change, vol. 126, Jan, pp. 126-137. Issue: 'Special Section: General Morphological Analysis: Modelling, Forecasting and Innovation', T Ritchey \& T Arciszewski (eds). arXiv:1706.08966. doi:10.1016/j.techfore.2017.05.007.

Whitehead, AN 1978, Process and reality: an essay on cosmology, Corrected edn, Free Press, New York. Gifford Lectures delivered in the University of Edinburgh during the session 1927-28. Edited by David Ray Griffin and Donald W. Sherburne.

Wilber, K 1995, Sex, ecology, spirituality: the spirit of evolution, Shambhala Pubs., Boston.

1996a, The Atman project: a transpersonal view of human development, 2nd edn, Quest Books, Wheaton, IL, USA. Originally published 1980.

1996b, Up from Eden: a transpersonal view of human evolution, 2nd edn, Quest Books, Wheaton, USA. Originally published 1981.

1997, 'An integral theory of consciousness', Journal of Consciousness Studies, vol. 4, no. 1, Feb, pp. 71-92.

1999-2000, The collected works of Ken Wilber, 8 vols, Shambhala Pubs., Boston. vols 1-4 published 1999; vols 5-8 published 2000.
2006, Integral spirituality: a startling new role for religion in the modern and postmodern world, Shambhala Pubs, Boston.

2007, The integral vision: a very short introduction to the revolutionary Integral approach to life, God, the universe, and everything, Shambhala Pubs, Boston.

2016, Integral meditation: mindfulness as a path to grow up, wake up, and show up in your life, Shambhala, Boulder. Also available as Kindle and Audible editions.

2017, The religion of tomorrow: a vision for the future of the Great Traditions-more inclusive, more comprehensive, more complete, Shambhala, Boulder. Also available as Kindle and Audible editions.

Wilber, K, Engler, J and Brown, DP (eds) 1986, Transformations of consciousness: conventional and contemplative perspectives on development, New Science Library, Shambhala, Boston. Reprinted in Vol. 3 of the Collected Works of Ken Wilber.

Wright, R 2017, Why Buddhism is true: the science and philosophy of meditation and enlightenment, Simon and Schuster, New York. Also available as Kindle and Audible editions.

Zalasiewicz, J, Crutzen, PJ and Steffen, W 2012, 'The Anthropocene', in FM Gradstein, JG Ogg, MD Schmitz \& GM Ogg (eds), The Geologic Time Scale, vol. 1, Elsevier, Boston, Chap. 32, pp. 1033-1040. doi:10.1016/ B978-0-444-59425-9.00032-9.

Zeleny, M 1981, 'Erich Jantsch (1929-1980)' [Obituary], Human Systems Management, vol. 2, no. 2, Jul, pp. 118120. doi:10.3233/hsm-1981-2208. 